R Giridhar, Deepak Gaikwad, Jayadatta Lad (2018). "Knowledge Management and its application in developing Lean Culture." In: Proc. $26^{\text {th }}$ Annual Conference of the International. Group for Lean Construction (IGLC), González, V.A. (ed.), Chennai, India, pp. 1090-1100. DOI: doi.org/10.24928/2018/0415. Available at: www.iglc.net

\title{
KNOWLEDGE MANAGEMENT AND ITS APPLICATION IN DEVELOPING LEAN CULTURE
}

\author{
R Giridhar ${ }^{1}$, Deepak Gaikwad ${ }^{2}$, Jayadatta Lad $^{3}$
}

\begin{abstract}
Construction projects generate a lot of learning during their lifecycle. However, it is common to see this learning go underutilized in subsequent projects. If an organization learns to control the "waste of knowledge" during the project lifecycle and utilize this knowledge in subsequent projects, it can form a significant competitive advantage for the organization.

Knowledge management (KM) is defined as the process of capturing, managing, and disseminating the knowledge of an organization.

This paper presents our experience of implementing of an award-winning knowledge management system for construction projects and explores how knowledge management activities facilitate and enable to build lean culture within an organization. It shows how our KM system allows for "information pulling" by project team members to get the correct information, to the right people, in the relevant form, at the appropriate time. We show how different facets of KM aid in promoting Lean Principles and through examples from our projects, how Lean Culture can be developed by sharing best practices and learning from past projects.
\end{abstract}

\section{KEYWORDS}

Knowledge management, Lean Culture, Lean Principles, Knowledge Enterprise

Executive Director (Technical), Afcons Infrastructure Ltd, India, giridharr@afcons.com

Dy. General Manager, Afcons Infrastructure Ltd, India, deepak@afcons.com

EA to Executive Director (Technical), Afcons Infrastructure Ltd, India, jayadatta.lad@afcons.com 


\section{INTRODUCTION}

In a highly competitive sector like construction, retention and use of an organization's knowledge assets can offer a significant competitive advantage. Construction projects have potential to be rich sources of knowledge for the organization. Generally, this knowledge is in the form of knowledge of individual project managers, construction managers, engineers, and designers rather than the collective knowledge of the organization. Sharing this knowledge has many benefits. It minimizes the learning process from past projects, reduces the time and cost of problem-solving, and improves the solution quality during the construction phase of a construction project. (Lin and Tserng, 2003).

However, given the scale, complexity, diversity, uniqueness and geographic dispersion of these projects, acquiring this knowledge becomes a challenge. This challenging environment can result in this knowledge going uncaptured. This 'waste of knowledge' results in organizations 'wasting time and money' during a project's life cycle to 're-invent the wheel', to do re-work or for failed bids. (Gannon and Banham, 2011)

This paper attempts to show how Afcons' Knowledge Management system aids in promoting Lean Principles and through examples from our projects, how Lean Culture can be developed by sharing best practices \& learning from past projects, identifying \& reducing wastes in activities, recognising \&respecting people expertise and driving continuous improvement.

\section{KNOWLEDGE MANAGEMENT}

Knowledge is commonly categorised in practice and literature as explicit and tacit knowledge (Gannon and Banham, 2011). Explicit knowledge is formal knowledge that can be expressed through language or symbols, whereas tacit knowledge is knowledge known by an individual through experience and internal reflection (Anumba et al.) and distributed throughout an organization. Project knowledge includes explicit information such as project records and documentation and tacit knowledge such problems faced, solutions developed, expert suggestions, innovations and knowledge gained from project successes and failures.

According to Davenport \&Prusak (1998) Knowledge Management (KM) is managing the organisation's knowledge by a systematic and sustainable process for capturing, organizing, applying, disseminating and replenishing both the tacit and explicit knowledge of employees to create value and improve the performance of the organizational. According to Gannon and Banham (2011), the challenge with managing Tacit knowledge in a project environment is how to recognize, generate, share and manage the knowledge between team members and then how to transfer this knowledge to the organization.

\section{ABOUT AFCONS}

AFCONS Infrastructure Ltd. (Afcons) is the flagship Infrastructure Construction Company of $\mathrm{M} / \mathrm{s}$ Shapoorji Pallonji Group the second largest Engineering and 
Construction group in India, (a group in existence for more than 150 years with businesses in India \& 60 other countries). Afcons has experience of over five decades of infrastructure construction in Marine works, Highways / Expressways, Bridges, Railway\& Metro works, Barrages, Tunnels, Oil \& Gas, LNG Tanks \& facilities serving both Government as well as Private Clients. Afcons has completed over 350 Infrastructure projects across 15 countries, including India, Africa, South Asia \& Middle East, generating revenue of ` 65 billion ( 1 Bn USD) in FY 2017-18.

\section{AFCONS LEAN JOURNEY}

Afcons' Lean journey began in 2008 as one of the founder members of Institute for Lean Construction Excellence. Under the guidance of the Executive Director - Technical, a team of 3 employees at Head Office anchor Lean Construction initiatives supported by Lean Champions at site. Over the years, several Lean implementation initiatives have been carried out at various projects. The Last Planner System ${ }^{\mathrm{TM}}$ has been studied and adopted. Several Lean tools such 5S, Standardized Work, Visual Management, Value Stream Mapping, Single Minute Exchange of Die etc.have been implemented successfully at different sites. More than 200 employees have been trained in Lean tools and principles through an E-learning module on Lean Construction. An extensive training program (Mission Dhanush) is in place to train each employee at every project on basic Lean tools and principles. Since 2016, adoption of BIM tools has also been initiated at several projects.

\section{AFCONS KM JOURNEY}

In 2012, Afcons started its Knowledge Management (KM) journey. KM was launched in three phases, an initial pilot, followed by official launch and finally KM introduction workshops and roll-out at project sites. The next two years were spent launching the Gnosis portal at different sites and building the content. To encourage users to use the Gnosis portal and contribute content, promotional campaigns were carried out. The lessons learned process was developed and initiated in 2014. In 2016, the knowledge organization was revamped and Knowledge Services Group was formed.In 2016\& 2017, Afcons' efforts in implementing Knowledge Management System was rewarded with the Global, Asian and Indian MAKE award (Most Admired Knowledge Enterprise) in the IOU (Independent Operating Unit) category. Currently a team of 12 employees anchors the organization's Knowledge Management related initiatives.

\section{KNOWLEDGE MANAGEMENT AT AFCONS}

At Afcons, KM process is based on three stage learning approach with designated inputs and favorable outputs. The outcomes of KM are helping constantly in cultivating a Lean culture within the organization. The three stages are as shown in Figure 1 


\section{LEARN BEFORE}

Knowledge at the right time, right place and right combination is an efficient key to informed decision making. Therefore, before the start of any new project, organizational knowledge needs to be transferred to the project team.

Project team can refer to the lessons learned reports, success stories and project completion reports of past projects which are readily available in KM portal (Gnosis) as a guide in adopting right practices and avoiding mistakes. Knowledge about the process can also be gained through process videos, animations and photographs which are stored in KM portal. Various standard project documents like method statements, Health, Safety, and Environment plan, Quality Approval plan, Inspection and Testing plan, formats, checklists etc. can also be referred from the portal, reducing the time required to prepare the documents and formats.

Kick off workshops are designed to be conducted at new project sites just before the start of execution. The newly assembled project team discusses the execution strategy with Heads of various departments. They also seek to know details of past project learning of similar nature. Experience of the experts is leveraged to fulfill the knowledge requirement of the project team.

The teams in projects can also enhance their domain knowledge by going through the e-Learning courses. The e-Learning courses are designed by taking practical inputs by experience of subject matter experts within the organization. In addition to this, Afcons has developed an extensive network of external experts and consultants, who help in introducing the latest ideas and best practices from across the world.

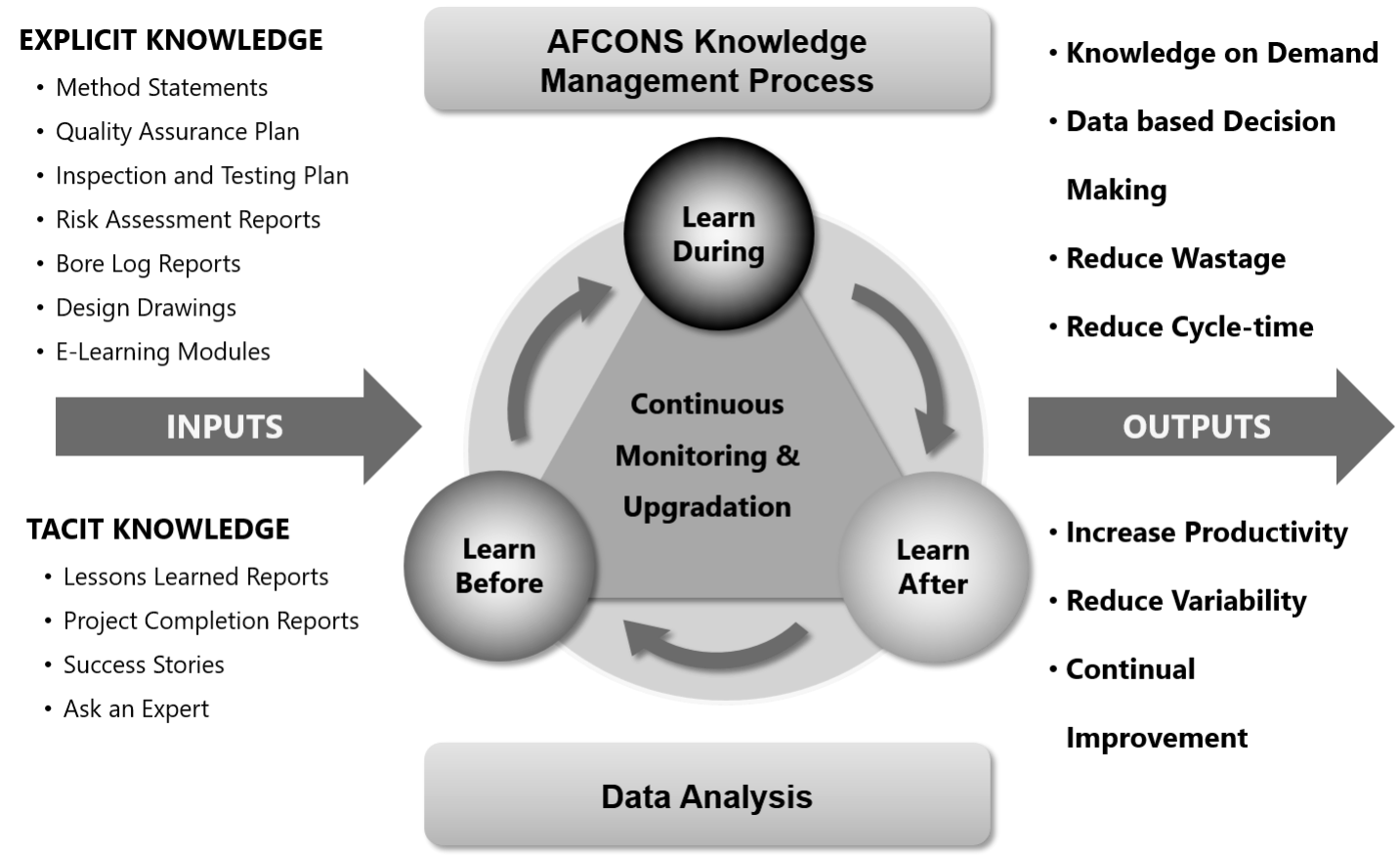

Figure 1: AFCONS Knowledge Management Process 


\section{LEARN DURING}

Continuous learning and improving the process is very important during the construction project. Afcons KM process makes it possible by providing learning support through Activity Based Classrooms, Classroom at Site, Ask an Expert, Technical Audio Visuals, Process Videos etc. as per the project demands.

Activity Based Classroom (ABC) is conducted just before the start of an activity in which an expert guides the project team through the intricacies of executing the activity. Expert illustrates the lessons learned which are captured from the previous projects and suggests the value engineering that can be done in the execution of the activity. There are even practical demonstrations associated with the $\mathrm{ABCs}$ that are performed at the sites. Classroom at Site is a platform where the engineer with the expertise in a specific domain shares his knowledge with the project team. Activity Based Classroom and Classroom at site share lot of similarities with First Run Studies (Howell and Ballard, 1999).

Ask an Expert feature in the KM portal connects the knowledge seeker and expert directly. This feature helps the user in getting the right solution from the expert for any question related to the project. Daily learning is ensured by Q\&A platform in KM portal in which a single question related to construction process is updated every day whose answer along with the description is made available next day. KM system also ensures the learning on new technologies and trends by facilitating the external trainings.

The KM team is also involved with small scale studies to help generate awareness about the better operating processes that can be implemented within the organization either by the intervention of technology or streamlining the existing operations. These are published in the form of a technical bulletin quarterly.

Cross transfer of knowledge between projects in real time basis happens through group of experts who visit various projects frequently. The Core Methods and Engineering Group (CMEG) and Budget Task Force (BTF) are two such examples of experts who help cross pollinate knowledge across various projects

\section{LEARN AFTER}

Knowledge created within a project life cycle is captured, classified and stored into domain knowledge and process knowledge. Lessons learned sessions are conducted with the objective of capturing lessons and insights for future projects to perform better. The motto is every time we do something; we should be able to do better than the last time. Efforts are taken to identify different situations where these learning can be applied. During the lessons learned session the entire project team gets an insight of the job executed.

Since the project moves forward activity wise, the lessons learned is captured at 60$70 \%$ completion of major activities. It is prudent to capture the learnings at this stage, as project team members start getting assigned to other activities/projects as the activity approaches completion. These lessons learned are stored in the form of reports and uploaded in KM portal for use in parallel or new similar projects. The captured lessons learned throughout the lifecycle of the project are consolidated the end of the project. 
This in turn churns out a final lesson learned report for the entire project. The major outcomes expected from a lesson learned session are:

- What was expected to happen?

- What were the assumptions?

- What happened?

- What went well and why?

- What did not go well and why?

- What could have been done differently?

The report is further checked and reviewed by experts before upload to the KM portal (Gnosis) for use in future projects. The critical lessons learned points from past projects are disseminated as per the project team's "pull information demand" which increases the acquaintance of the project team with anticipatory circumstances and equips them with the capability to implement the technically and commercially viable solutions. Table 1 brief describes the various KM activities undertaken at Afcons

Table 1: Brief description of KM activities

\begin{tabular}{ll}
\hline KM activity & Description \\
\hline $\begin{array}{l}\text { Activity Based } \\
\text { Classroom }\end{array}$ & $\begin{array}{l}\text { Training session at project site by external facilitator on a critical activity } \\
\text { before start of the activity. } \\
\text { Pushed by KM team }\end{array}$ \\
\hline Classroom at Site & $\begin{array}{l}\text { Training session at project site by one of the members of the project team, } \\
\text { who is expenced in an activity, before start of the activity. } \\
\text { Pulled by the project team }\end{array}$ \\
\hline Ask an Expert & $\begin{array}{l}\text { Feature of Gnosis portal to request for help from designated experts on } \\
\text { site }\end{array}$ \\
\hline Pulled by individual \\
Community of & $\begin{array}{l}\text { Online community of people with deep expertise and passion for a } \\
\text { domain of work } \\
\text { Pulled by individual }\end{array}$ \\
\hline $\begin{array}{l}\text { KM Portal } \\
\text { Gnosis) }\end{array}$ & Online training module with interactive content \\
\hline
\end{tabular}


Pulled by project team, at times pushed by KM team

\begin{tabular}{ll}
\hline $\begin{array}{l}\text { Kickoff } \\
\text { Workshops }\end{array}$ & $\begin{array}{l}\text { Information sharing workshop during the initial stage of the project, to } \\
\text { ensure Client expectations are communicated clearly to each project team } \\
\text { member } \\
\text { Pushed by KM team }\end{array}$ \\
\hline CMEG, BTF & $\begin{array}{l}\text { Team of experts with deep domain knowledge in particular area of work } \\
\text { Pulled by project team }\end{array}$ \\
\hline Lessons Learned & $\begin{array}{l}\text { Workshop to capture what went well, what did not go well and lessons for } \\
\text { the future } \\
\text { Pushed by KM team }\end{array}$ \\
\hline
\end{tabular}

\section{KM AS AN ENABLER OF LEAN CULTURE}

Lean is a comprehensive approach to create value by eliminating waste in an organisation. It incorporates everything from single processes, management, organisational culture and structure. Within Lean, seven types of wastes have been identified: over-production, waiting, transportation, over processing, inventory, defects and motion. 'Waste of knowledge' as another type of waste that can be added to this list.

In Lean, a push system releases work based on demand, whereas a pull system releases work based on system status (Hopp and Spearman 1996). (Ahn et al., 2007) have defined "information pulling" as delivering prerequisite knowledge of the successor activity at the time that project participants are ready for that activity. The key purpose in "information pulling" is to make the information system know when to deliver prerequisite knowledge for a succeeding activity.

Our KM system allows both; content to be pushed to the learner and the learner to pull the content. Content can be pushed to Learner through Activity Based Classrooms, Classroom at Site, and Kick-off workshop. This content is decided based on the type of project, with the aim of ensuring that most project team members are made aware of the critical aspects and activities for the success of the project. Apart from this, the Learner can pull the content through the KM portal (Gnosis), E-learning, Ask an Expert, Project completion reports and Lessons learned. This enables the learner to quickly reinforce or upgrade his skill, find solutions to problems and identify improvements/innovations to improved performance. It ensures that mistakes made in earlier projects are not repeated. Improvements made through lean initiatives can hence be effectively deployed horizontally to ensure transmission throughout the organisation.

Lean does not force change, but rather builds on successful practices and procedures as well as inspires employees themselves to make suggestions for change. Continuous improvement of Lean process requires long-term commitments from top management and employees. Hence building a Lean culture is a key factor in successful implementation of Lean. KM promotes development of a learning organisation and efforts to eliminate waste and improve construction processes will invariably require 
sharing and transferring knowledge from previous projects and later to transfer the learning from Lean initiatives to new projects.

At its core, Afcons KM system helps to reduce waste that happens due to mistakes being repeated from project to project. At the same time, it allows project team members to connect, explore ideas for improvement and build on previous successes and failures. It enables continuous improvement in how construction activities are performed. Therefore, several lean initiatives at Afcons are aligned with KM activities. Value Stream Mapping is embedded in Activity Based Classrooms. At the same time, Activity Based Classrooms are aligned with First Run Studies ((Howell and Ballard, 1999).Experience and output from Standardised Work and Visual Management are captured on the KM portal for future reference. Experience in using Last Planner System ${ }^{\mathrm{TM}}$, especially Constraint Log, Make-Ready and PPC charts are crucial to identify lessons learned.

Lean initiatives and KM system are tightly coupled. On several occasions, promotional campaigns for KM system have identified Lean improvements which project team members have been able to achieve on their own. An effective KM system not only enables development of Lean Culture, but in fact accelerates the pace of adoption.

The pillar of Lean is the adoption of its six principles - value, value stream, flow, pull, perfection, and respect for people. Table 2 describes the facets of our Knowledge Management system that supports and enables various Lean principles.

Table 2: Lean Principles supported by Knowledge Management 


\section{Lean Principle Lean Enabler \\ 1. Classroom at site and E-Learning help users develop themselves professionally \\ Respect for \\ People \\ 2. Rewards and recognitions help to highlight knowledge contributors \\ 3. GNOSIS portal offers several features to come up to speed about different areas of construction \\ 4. Community of people enables users to connect with others to share thoughts, problems and solutions}

1. Lessons learned \& Project completion reports(PCR) demonstrate how the project can enhance value for the customer

Value

2. Kick-off workshops help to bring the entire project team on the same table and create awareness regarding customer's requirements

3. K-capsules \& success stories help to share innovations across the organization

4. KM team utilizes experts (CMEG) to innovate on methods

1. Users can use GNOSIS portal to explore multiple solutions simultaneously for their problems through PCRs, methods \& Ask an Expert

Value Stream 2. Kickoff Workshop and Activity based Classroom help to identify and ensure that capabilities to deliver a project are available up-front

3. Project completion reports and method statements offer insight into the productivity parameters and ways variability in a process can be reduced

1. Community of Practice and Ask an Expert feature allow users to discuss their problems in an open forum and get feedback from experts

Flow\& Pull 2. Methods and process videos enable to standardize work procedures and standard operating procedures to increase efficiency

3. GNOSIS, PCRs, E-Learning etc. offer knowledge on demand to ensure preparedness before starting a new activity

1. Lessons Learned from the projects are captured effectively and are easily accessible to users to avoid repeating mistakes

Perfection 2. Project completion reports, lessons learned and other project documents help users identify key risks and effective mitigation measures

3. Method statements and lessons learned enable users to identify baseline benchmarks which they can strive to exceed 


\section{EXAMPLES}

At a metro construction project in eastern India, we had to construct an underground metro station building. The Knowledge Services Group team identified the execution expert from a similar project in south India. The expert prepared a presentation highlighting the learnings they had got from their project experience and the good practices that could be adopted. Post review, the expert was sent to the project to conduct an Activity Based Classroom for training the project team to execute underground station buildings. This ensured that mistakes made in the earlier project were not repeated, and were in fact, proactively avoided.

At a marine wharf project in Western India, piling cycle-time was not being achieved as planned. Hence Value Stream Mapping exercise was conducted to identify how to make value flow and remove wastes. During the exercise, it was observed that defects from liner fabrication yard and reinforcement cage fabrication yard were flowing downstream and impacting piling cycle-time. The checklist for the finished product at both the yards were modified to incorporate the checks for defects and thereafter standardised. The case was also captured as lessons learned for future reference and shared with similar projects.

The Ask an Expert feature on the Gnosis portal is used extensively by the on-going project teams. One such instance is of the Sulphur Handling Facility in Middle East. The project team was facing problem for under water pile cleaning and painting in the splash zone. The experts from head office discussed the problem with the project team and then searched for similar kind of issue on the KM portal. They found a solution in the form of a method statement for similar works from a past project in Mauritius. A cofferdam arrangement scheme for pile painting in splash zone was proposed to the project team which the team executed to complete the activity within the scheduled time. This is an example of how the project team 'pulled information' at the right time to enable them to complete the work as per schedule.

At times, due to criticality of an activity it is necessary to both, "push" as well as "pull" knowledge. An expressway project in northern India, had a time-sensitive and critical bridge over a major river. Delays in fabrication of the launching truss, resulted in the team exploring ways to improve launching cycle-time. The team studied methods for launching at other projects. At the same time, CMEG group of experts conducted an Activity Based Classroom to explore how to improve the cycle-time. The team were able to identify several areas where time could be saved, as well as some improvements through innovations. As a result, the launching cycle-time was reduced by half, to a record time.

\section{CONCLUSION}

The application of Lean principles is very challenging in the construction industry. This paper attempted to show how Lean Construction implementation and KM system are linked and inter-connected and how KM can be an enabler for building a Lean Culture. It first introduced the concept of knowledge and $\mathrm{KM}$ and then discussed how Afcons implements its knowledge management system. Further it discussed how KM enables 
Lean Culture by preventing 'waste of knowledge', satisfying 'information demand' to the right person, at the right time and in the right form and supporting transfer of learning from Lean initiatives to new. Preventing 'waste of knowledge' can form a significant competitive advantage by minimising the learning process from past projects, faster learning curve, reduce the time and cost of problem-solving, improving the solution quality and reducing waste and improving cycle-times. At the end, examples were used to illustrate how KM system helped to deliver value for the project. Development of a Lean Culture is a slow and gradual process and an effective KM system acts a catalyst to accelerate the adoption of Lean principles.

\section{ACKNOWLEDGMENTS}

The authors would like to thank the management and employees of AFCONS Infrastructure Ltd in whole heartedly supporting the journey of Knowledge Management and Lean Construction.

\section{REFERENCES}

Ahn, C., Park, M., Lee, H., and Roh, S. (2007). "Project based knowledge management system for Lean Construction" Proc. Fifteenth Annual Conference of the International Group for Lean Construction (IGLC-15), Michigan, USA, 549-558

Anumba, C.J.,Egbu, C.O. and Carrillo, P.M. (2005). Knowledge Management in Construction. Blackwell Publishing.

Davenport, T.H. and Prusak, L. (1998) Working Knowledge: How Organisations Manage What They Know. Cambridge, MA: Harvard Business School Press.

Gannon, M. and Banham, G. (2011). "Managing knowledge in construction engineering projects." OR Insight Vol. 24, 1, 17-30

Hopp, W. and Spearman, M. (1996). Factory Physics. McGraw Hill Higher Education, Columbus, $317 \mathrm{pp}$.

Lin, Y. and Tserng, H. P. (2003). "Knowledge Management and its application to Lean Construction." Proc. Eleventh Annual Conference of the International Group for Lean Construction (IGLC-11), Virginia, USA, 542-552.

Howell, G. and Ballard, G. (1999). "Design of Construction Operations", LCI Whitepaper - 4, Lean Construction Institute Implementation Workshop, Portland, USA, 